\title{
Willingness to pay for beef is highly transferrable between different consumer groups
}

\author{
S. P. F. Bonny $y^{1,2, a t}$, J.-F. Hocquette ${ }^{2,3}$, D. W. Pethick ${ }^{1}$, I. Legrand ${ }^{4}$, J. Wierzbicki' ${ }^{5}$, P. Allen ${ }^{6}$, \\ L. J. Farmer ${ }^{7}$, R. J. Polkinghorne ${ }^{8}$ and G. E. Gardner ${ }^{1}$ \\ ${ }^{1}$ School of Veterinary and Life Sciences, Murdoch University, Murdoch, WA 6150, Australia; ${ }^{2}$ INRA, UMR1213, Recherches sur les Herbivores, F-63122, Saint-Genès- \\ Champanelle, France; ${ }^{3}$ Clermont Université, VetAgro Sup, UMR1213, Recherches sur les Herbivores, F-63122, Saint-Genès-Champanelle, France, ${ }^{4}$ Institut de \\ I'Elevage, Service Qualite' des Viandes, MRAL, 87060 Limoges, Cedex 2, France; ${ }^{5}$ Polish Beef Association Ul, Kruczkowskiego 3, $00-380$ Warszawa, Poland; \\ ${ }^{6}$ Teagasc Food Research Centre, Ashtown, Dublin 15, Ireland; ${ }^{7}$ Agri-Food and Biosciences Institute, Newforge Lane, Belfast, BT9 5PX, UK; ${ }^{8}$ Birkenwood Pty Ltd, \\ 431 Timor Road, Murrurundi, NSW 2338, Australia
}

Accurately quantifying a consumer's willingness to pay (WTP) for beef of different eating qualities is intrinsically linked to the development of eating-quality-based meat grading systems, and therefore the delivery of consistent, quality beef to the consumer. Following Australian MSA (Meat Standards Australia) testing protocols, over 19000 consumers from Northern Ireland, Poland, Ireland, France and Australia were asked to detail their willingness to pay for beef from one of four categories that best described the sample; unsatisfactory, good-every-day, better-than-every-day or premium quality. These figures were subsequently converted to a proportion relative to the good-every-day category $(P$-WTP) to allow comparison between different currencies and time periods. Consumers also answered a short demographic questionnaire. Consumer P-WTP was found to be remarkably consistent between different demographic groups. After quality grade, by far the greatest influence on P-WTP was country of origin. This difference was unable to be explained by the other demographic factors examined in this study, such as occupation, gender, frequency of consumption and the importance of beef in the diet. Therefore, we can conclude that the P-WTP for beef is highly transferrable between different consumer groups, but not countries.

Keywords: consumer testing, beef, value, demographics, Europe

\section{Introduction}

Accurately quantifying a consumer's willingness to pay for beef of different eating qualities is intrinsically linked to the development of eating-quality-based meat grading systems, and therefore the delivery of consistent, quality beef to the consumer. It has been demonstrated that consumers from Australia, America, Japan and South Africa consider premium beef to be worth double than every-day quality beef (Lyford et al., 2010; Thompson et al., 2010). However, this price differential can only be realised when eating quality information is available to the consumer, necessitating the development of a quality-based meat grading system.

In Australia, the commercial, eating-quality-based grading system called MSA (Meat Standards Australia) has increased the value of the domestic beef industry by 77 million Australian dollars annually, in 2010/11, and by 523 million since its inception (Griffith and Thompson, 2012).

While the overall trend was for willingness to pay to double for premium beef, this was influenced by

\footnotetext{
a Present address: School of Veterinary and Life Sciences, Murdoch University, Murdoch, WA 6150, Australia.

† E-mail: spfbonny@gmail.com
}

demographic factors. Consumer age has been found to have a negative relationship with willingness to pay, with consumers between 20 and 35 willing to pay more for premium beef than consumers aged 51 and above (Lyford et al., 2010; Thompson et al., 2010). This was seen in Australia, Japan, the United States, Ireland and South Africa. Besides age, there are several other demographic factors that have been investigated and found to have no effect on willingness to pay for quality beef. No effect of sex, occupation, number of children in the household or cooking method was found for Australian, Japanese, American, Irish and South African consumers (Lyford et al., 2010; Thompson et al., 2010; Reicks et al., 2011). In addition, Feuz et al. (2004) found no effect of income bracket on willingness to pay for American consumers. In addition, Feuz et al. (2004) and Reicks et al. (2011) found that these patterns were similar across different regions in the United States. Therefore we would expect that the trend would also continue to European consumers.

This paper looks at consumers from France, Poland, Ireland, Northern Ireland and Australia who indicated their willingness to pay for four different quality levels of beef, unsatisfactory, good-every-day, better-than-every-day and premium. Based on the balance of the testing in other 
Willingness to pay for beef is highly consistent

countries, we hypothesise that there will be no effect of demographic factors on willingness to pay, outside of a negative relationship with consumer age. Other aspects of the data, including the effect of consumer age, have been examined in a series of two papers in Animal (Bonny et al., 2017a and 2017b).

\section{Material and methods}

Animals, muscle samples and preparation

The carcasses used for this experiment are described in detail by Bonny et al. (2016). In brief, the data set was formed through combining the records of a number of specific, smaller, experiments. As a result, this data set provides a cross-section of European cattle types from France, Poland, Ireland and Northern Ireland. A total of 25 different muscles were collected, though not all muscles were collected from each carcass.

Meat preparation and consumer assessment of eating quality for the four cooking methods were performed according to protocols for MSA testing by personnel trained in MSA testing procedures (Watson et al., 2008). The grill cooking method was performed in all countries and the roast cooking method was performed in all countries except for France. Grill samples were prepared to either a rare or a medium doneness in France. In Northern Ireland, the roast and grill samples were prepared to either a medium or a well-done cooking doneness. All other samples were prepared to a medium cooking doneness. The slow cooking method was only used in Poland and the Korean BBQ was tested only in Ireland.

\section{Consumer demographics and questionnaires}

The consumers and the experimental design are outlined in further detail by Bonny et al. (2017a). In brief, consumers filled out a short demographic questionnaire, then participated in a sensory panel where they were asked to allocate beef samples into one of four categories that best described the sample; unsatisfactory, good-every-day, better-thanevery-day or premium quality. After the completion of the tasting panel, consumers were then asked to detail, in their own currency, their willingness to pay for these four categories. All consumers indicated their willingness to pay by marking a point on a line, except for the Irish consumers who were required to tick a box indicating a fixed value. The results from the questionnaire are outlined by Bonny et al. (2017a and 2017b).

\section{Statistical analyses}

Willingness to pay, expressed as a proportion of good-everyday (P-WTP), was analysed using a linear mixed effects model (SAS v9.1). The fixed effects are outlined in Table 1. All fixed effects were interacted with country and quality grade. Non-significant terms $(P>0.05)$ were then removed in a step-wise fashion to arrive at the final model. The predicted means were compared using the LSD, generated using the PDIFF function in SAS (SAS v9.1).

\section{Results}

\section{Linear mixed effects model}

Outcomes from the model are presented in by Bonny et al. (2017a). As would be expected, the quality grade had by far the biggest effect on P-WTP. This was followed by country, which also had a large effect. The demographic effects, age and income, also had a small effect. Of all the effects tested in the model, six effects were found to have no effect on P-WTP for beef, consumer gender, occupation, preferred level of doneness, numbers of children and adults in the household, and the cooking method used in the session.

\section{The effect of the frequency of beef consumption on proportional willingness to pay}

Consumers from France who ate beef fortnightly or less had a higher P-WTP by $\sim 0.5$ for both better-than-every-day and premium beef than consumers who ate beef more frequently (Table 1) $(P<0.05)$. Consumers who ate beef two to three times a week had a higher P-WTP for premium beef than consumers who ate beef weekly $(P<0.05)$, though this difference was much smaller (Table 1). No other countries or consumer groups showed any significant differences.

\section{The effect of income on willingness to pay}

Only consumers from France and Poland showed differences in willingness to pay between income groups (Table 2). French consumers exhibited a slight increase in P-WTP for better-than-every-day quality in the high and low income groups $(P<0.05)$. Similarly, French consumers with incomes of $€ 1000$ to $€ 2000$ and greater than $€ 6000$ per month were willing to pay proportionally more for premium beef than consumers in the middle income ranges $(P<0.05)$. In contrast the Polish consumers' P-WTP had a more direct relationship with income. P-WTP for premium beef from 1.87 to 1.98 times good-every-day as income increased from 1001 to $1400 z \mathrm{zl}$ per month to $4000 \mathrm{zl}$ per month and more $(P<0.05)$. Other countries showed no effect of income (Table 2).

Table 1 Predicted means for the willingness to pay expressed as a ratio of good-every-day for quality grade by the consumers frequency of eating beef for France

\begin{tabular}{llllll}
\hline \hline & \multicolumn{5}{c}{ Frequency of eating beef } \\
\cline { 2 - 6 } Quality grade & 1 & 2 & 3 & 4 & 5 \\
\hline France $^{1}$ & & & & & \\
$\quad$ Unsatisfactory & 0.38 & 0.37 & 0.38 & 0.38 & 0.39 \\
Good-every-day & 0.99 & 0.99 & 0.99 & 0.99 & 0.99 \\
Better-than-every-day & $1.67^{\mathrm{a}}$ & $1.70^{\mathrm{a}}$ & $1.71^{\mathrm{a}}$ & $1.65^{\mathrm{a}}$ & $2.16^{\mathrm{b}}$ \\
Premium & $2.56^{\mathrm{ab}}$ & $2.57^{\mathrm{ab}}$ & $2.57^{\mathrm{a}}$ & $2.49^{\mathrm{b}}$ & $2.98^{\mathrm{c}}$ \\
SE $^{2}$ & 0.148 & 0.095 & 0.090 & 0.091 & 0.104 \\
\hline \hline
\end{tabular}

$1=$ Daily; $2=$ four to five times a week; $3=$ two to three times a week; $4=$ weekly; $5=$ fortnightly or less.

${ }^{1}$ Willingness to pay was first expressed in euros and then as a proportion of good-every-day for quality grade.

${ }^{2}$ Standard error for each level of reported frequency of eating beef by country.

$a, b, c$ Values within a row with different superscripts differ significantly at $P<0.05$. 
Bonny, Hocquette, Pethick, Legrand, Wierzbicki, Allen, Farmer, Polkinghorne and Gardner

Table 2 Predicted means for willingness to pay expressed as a ratio of good-every-day for the quality grades for each income category for France and Poland

\begin{tabular}{|c|c|c|c|c|c|c|c|}
\hline \multirow[b]{2}{*}{ Quality grade } & \multicolumn{7}{|c|}{ Income $^{1}$} \\
\hline & 1 & 2 & 3 & 4 & 5 & 6 & 7 \\
\hline \multicolumn{8}{|l|}{ France } \\
\hline Unsatisfactory & 0.39 & 0.42 & 0.40 & 0.36 & 0.35 & 0.35 & 0.34 \\
\hline Good-every-day & 0.98 & 0.99 & 0.99 & 0.99 & 0.99 & 0.99 & 0.99 \\
\hline Better-than-every-day & $1.61^{\mathrm{a}}$ & $1.76^{\mathrm{b}}$ & $1.60^{\mathrm{a}}$ & $1.60^{\mathrm{a}}$ & $1.56^{\mathrm{a}}$ & $1.62^{\mathrm{ab}}$ & $1.85^{\mathrm{ab}}$ \\
\hline Premium & $2.17^{\mathrm{a}}$ & $2.40^{\mathrm{b}}$ & $2.22^{\mathrm{a}}$ & $2.21^{\mathrm{a}}$ & $2.22^{\mathrm{a}}$ & $2.33^{\mathrm{ab}}$ & $2.55^{\mathrm{b}}$ \\
\hline$S E^{2}$ & 0.089 & 0.075 & 0.075 & 0.076 & 0.095 & 0.143 & 0.159 \\
\hline \multicolumn{8}{|l|}{ Poland } \\
\hline Unsatisfactory & 0.54 & 0.54 & 0.53 & 0.52 & 0.50 & & \\
\hline Good-every-day & 1.00 & 1.00 & 1.00 & 1.00 & 1.00 & & \\
\hline Better-than-every-day & 1.42 & 1.36 & 1.40 & 1.39 & 1.41 & & \\
\hline Premium & $1.91^{\mathrm{ab}}$ & $1.87^{\mathrm{a}}$ & $1.92 b^{b}$ & $1.92^{\mathrm{ab}}$ & $1.98^{\mathrm{C}}$ & & \\
\hline $\mathrm{SE}^{2}$ & 0.046 & 0.044 & 0.041 & 0.041 & 0.044 & & \\
\hline
\end{tabular}

${ }^{1}$ Ranges for income groups vary by country. France (maximum standard error 0.09$)-1=<€ 1000 /$ month, $2=€ 1000$ to $€ 2000 /$ month, $3=€ 2000$ to $€ 3000 /$ month, $4=€ 3000$ to $€ 4000 /$ month, $5=€ 4000$ to $€ 5000 /$ month, $6=€ 5000$ to $€ 6000 /$ month, $7=>€ 6000 /$ month. Poland (maximum standard error 0.05$)-1=\leqslant 1000 \mathrm{z} / \mathrm{month}$, $2=1001$ to $1400 \mathrm{z} / \mathrm{month}, 3=1401$ to $2200 \mathrm{z} / \mathrm{month}, 4=2201$ to $4000 \mathrm{z} / \mathrm{month}, 5=>4000 \mathrm{z} / \mathrm{month}$.

${ }^{2}$ Standard error for each income category by country.

$a, b, c$ Values within a row with different superscripts differ significantly at $P<0.05$.

\section{Discussion}

The impact of income on proportional willingness to pay Validating our hypothesis, there was no relationship between income and P-WTP for the Australian, Irish and Northern Irish consumers. This is in alignment with the results of Lyford et al. (2010); Feuz et al. (2004) who also found no relationship between income and P-WTP for Australian, Japanese, American and Irish consumers.

However, in contrast to this, we found that income significantly influenced P-WTP for the French and Polish consumers, rejecting our hypothesis for these groups. Both the French and Polish consumers showed a positive relationship between income and P-WTP, where consumers with higher incomes were willing to pay proportionally more for premium quality beef. Interestingly, French consumers in the second lowest income category had a similar P-WTP as the higher income categories. This may represent a difference between the Polish and the French consumers, or may reflect a difference in the behaviour of French consumers within the middle income group specifically. This would require further investigation to reveal any other related factors. These results are supported by Reicks et al. (2011) who found that consumers with higher incomes did not consider price as important when purchasing beef. The positive relationship between income and P-WTP in both Poland and France is worth further investigation as it suggests there is a niche for high-quality-branded products.

\section{The impact of the frequency of eating beef on proportional} willingness to pay

In support of our hypothesis, there was no relationship between beef eating frequency and P-WTP in any of the countries tested except France. In the case of French consumers who ate beef fortnightly or less, they were willing to pay proportionally more for better-than every-day and premium beef.

It is unlikely that this difference stemmed from different proportions in the frequency of eating beef categories, as the French data had a similar range and distribution of consumers across the different frequency categories as the Australian, Irish and Northern Irish data. In contrast, Thompson et al. (2010) and Feuz et al. (2004) found a positive relationship between willingness to pay and the frequency of beef consumption in south African and American consumers. However, it is interesting to note that the French consumers with the lowest frequency of eating beef also had the highest P-WTP, therefore the French consumers who eat less beef may do so as they consider it a premium or luxury product (Hocquette et al., 2011).

The impact of sex, household structure, occupation and the importance of beef on proportional willingness to pay In agreement with our hypothesis, the demographic factors of gender, occupation, the number of adults in the home and the number of children in the home had no effect on P-WTP. This is supported by the results of Lyford et al. (2010) who also found no effect of these factors for Australian, Japanese, American and Irish consumers. These results are further corroborated by Reicks et al. (2011) who found that these demographic factors had no effect on the importance of price when consumers were making purchasing decisions.

\section{Conclusion}

Consumer willingness to pay for beef of different quality levels is remarkably consistent between different demographic groups. Where the willingness to pay does vary with demographic factors, by far the greatest influence is country of origin. The importance of meat in the diet also had a small effect. 
Therefore, we can conclude that the willingness to pay for beef is highly transferrable between different consumer groups, however factors other than those investigated in this study are responsible for the variation between nationalities.

\section{Acknowledgements}

This research was supported by Meat and Livestock Australia and Murdoch University. Data were obtained through the financial contributions of the European research project ProSafeBeef (Contract No. FOOD-CT-2006-36241), the Polish ProOptiBeef Farm to Fork project funded by the EU Innovative (POIG.01.03.01-00-204/09), the French 'Direction Générale de I'Alimentation' and FranceAgriMer, the Irish Department of Agriculture Food and The Marine under the FIRM programme, and the Northern Ireland Department of Agriculture and Rural Development 'Vision' programme. Furthermore, this project would not have been possible without the practical support of the Association Institut du Charolais, the Syndicat de Défense et du promotion de la Viande de Boeuf de Charolles and the gourmet restaurants 'Jean Denaud' and representatives of the beef industry across Europe.

\section{References}

Bonny SPF, Hocquette J-F, Pethick DW, Farmer LJ, Legrand I, Wierzbicki J, Allen P, Polkinghorne RJ and Gardner GE 2017a. Untrained consumer assessment of the eating quality of beef: 1 . A single composite score can predict beef quality grades. Animal 11, 1389-1398.
Bonny SPF, Hocquette J-F, Pethick DW, Farmer LJ, Legrand I, Wierzbicki J, Allen P, Polkinghorne RJ and Gardner GE 2017b. Untrained consumer assessment of the eating quality of beef: 2 . Demographic factors have only minor effects on consumer scores and willingness to pay. Animal 11, 1399-1411.

Bonny SPF, Hocquette J-F, Pethick DW, Farmer LJ, Legrand I, Wierzbicki J, Allen P, Polkinghorne RJ and Gardner GE 2016. The variation in the eating quality of beef from different sexes and breed classes cannot be completely explained by carcass measurements. Animal 10, 987-995.

Feuz DM, Umberger WJ, Calkins CR and Sitz B 2004. U.S. consumers' willingness to pay for flavor and tenderness in steaks as determined with an experimental auction. Journal of Agricultural and Resource Economics 29, 501-516.

Griffith GR and Thompson JM 2012. The aggregate economic benefits to the Australian beef industry from the adoption of meat standards Australia: updated to 2010/11. Australasian Agribusiness Review 20, 11-38.

Hocquette J-F, Legrand I, Jurie C, Pethick DW and Micol D 2011. Perception in France of the Australian system for the prediction of beef quality (Meat Standards Australia) with perspectives for the European beef sector. Animal Production Science 51, 30-36.

Lyford C, Thompson J, Polkinghorne R, Miller M, Nishimura T, Neath K, Allen P and Belasco E 2010. Is willingness to pay (WTP) for beef quality grades affected by consumer demographics and meat consumption preferences? Australasian Agribusiness Review 18, 1-17.

Reicks AL, Brooks JC, Garmyn AJ, Thompson LD, Lyford CL and Miller MF 2011. Demographics and beef preferences affect consumer motivation for purchasing fresh beef steaks and roasts. Meat Science 87, 403-411.

Thompson J, Polkinghorne R, Gee A, Motiang D, Strydom P, Mashau M, $\mathrm{Ng}$ 'ambi J, deKock R and Burrow H 2010. Beef palatability in the Republic of South Africa: implications for niche-marketing strategies. In ACIAR technical reports, pp. 1-56. Australian Centre for International Agricultural Research ACIAR, Canberra, ACT, Australia.

Watson R, Gee A, Polkinghorne R and Porter M 2008. Consumer assessment of eating quality - development of protocols for Meat Standards Australia (MSA) testing. Australian Journal of Experimental Agriculture 48, 1360-1367. 